\title{
THE BEHAVIOUR OF REINFORCED CONCRETE BEAMS UNDER CYCLIC LOADING
}

\author{
R.C. Fenwick* and A. Fong **
}

\begin{abstract}
SYNOPSIS
The behaviour of beams in which plastic hinges are formed under cyclic loading is examined. The results are reported of five beam tests, in which the shear stress level was varied. It is shown that even relatively low shear stress levels have a significant influence on beam behaviour. Two main effects of shear are to reduce the ability of the hinge to dissipate energy and to reduce the stiffness of the beams at low load levels. The degradation in shear under cyclic loading is accompanied by an appreciable growth in length of the beam.
\end{abstract}

\subsection{INTRODUCTION}

To ensure ductile behaviour under seismic conditions most modern multistorey frame structures in New Zealand are designed to form plastic hinges in the beams. To prevent collaps these hinges must be capable of withstanding high inelastic rotations, usually in both directions, and of dissipating an appreciable amount of energy without suffering appreciable strength degradation.

Several series of tests have been made to assess the performance of beams under seismic conditions. Under the reversed loading involving inelastic extension of the reinforcement (which is typical of seismic loading), failure has frequent $I_{Y}$ been found to occur in a different manner from that in a beam subjected to monotonic loading. Tests have shown that the shear resisted by the concrete decreases under these such conditions, and a diagonal tension type of shear failure may occur unless adequate web reinforcement is provided $(1,2,3)$. In assessing the area of stirrups required to prevent this form of failure the shear resisted by the concrete in the region of the beam where the flexural tension steel yields, should be taken as zero. In addition, allowance should be made for the greater shear which may be sustained in the bearn due to the yield point of flexural reinforcement being greater than the specified minimum value (overstrength), and to its subsequent strain hardening. However, even in beams in which the web reinforcement meets these requirements a different form of shear failure may occur in the plastic hinge zone. This has been described as a sliding shear failure $(1,5)$.

To prevent sliding shear failures occurring in cpupling beams between shear walls Paulay (I) recommended that the shear stress level should not exceed $0.5 \sqrt{f_{C}^{1}}$ unless diagonal reinforcement was used in the web. In assessing the shear stress level in these beams, allowance should be made for the overstrength and strain hardening of the flexural reinforcement. From a series of tests carried out at Berkeley $(2)$ on beams typical of those

* Senior Lecturer in Civil Engineering Dept., University of Auckland.

* * Engineer with Auckland City Council. found in frame buildings it was concluded that a cyclic shear stress in excess of $0.29 \sqrt{f_{C}^{i}}$ in the plastic hinge zone could be expected to lead to a significant reduction in the energy dissipated in the hinge. This degradation arises as the deformation in shear is associated with only a small energy absorption.

From a review of previous tests Paulay $(3,4)$ proposed design limits for shear stress levels in beams subjected to reversed hinging under seismic conditions. The most recent of these proposals, which has been incorporated in the draft N.Z. code (4), limits the shear stress level " $v_{u}$ " in conventionally reinforced beams to:

$v_{u} \leq 0.3(2+r) \sqrt{f_{C}^{\prime}}$

where $r$ is the ratio of the shear forces under positive and negative flexural hinging at the section being considered, and its limits are 0 and -1 . The shear stress is calculated assuming a capacity reduction factor of 0.85 , and allowance is made for the likely overstrength and strain hardening of the flexural reinforcement (25\% for steel with a yield stress of $275 \mathrm{MPa}$ ).

The quantity and arrangement of web reinforcement in a beam has been found to have a very significant influence on its behaviour under reversed loading. As previously noted it has been recommended that the web reinforcement is proportioned to resist all the shear thus preventing a diagonal tension type of shear failure. In addition to this it has been found necessary to detail the stirrups at close centres to hold the flexural reinforcement from buckling. With yielding of the steel the deformed bars are displaced through the concrete towards the adjacent flexural cracks. The deformations move through the concrete breaking it up. When this zone is subjected to compression the bars yield back through the concrete causing further disruption and accelerating the tendency for the cover to spall off. The reinforcement softened by the reversed loading (Bauschinger effect) and no longer confined by the concrete is much more susceptible to buckling than in a monotonically loaded beam. The improved performance of beams where the flexural reinforcement has 
been adequately restrained by stirrups has been demonstrated by tests $(5,6)$.

Closely spaced stirrups improve the confinement of the concrete. Comparative tests have shown that where such reinforcement is combined with some longitudinal bars and cross ties in the mid regions of the web a further significant improvement occurs in the shear performance of the hinge zone due to the improved confinement of the web $(6)$.

The use of diagonal reinforcement in a beam has been shown to be a very effective means of reducing degradation under high shear stresses $(1,2,7)$. However, the added complexity involved in the steel placing detracts from this solution. In this paper only the performance of conventionally reinforced beams is considered, where the reinforcing bars are restrained against buckling at centres not exceeding the smaller of six bar diameters nor $100 \mathrm{~mm}$ centres, and the web reinforcement is proportioned to resist all the shear (making allowance for overstrength and strain hardening of flexural reinforcement).

\subsection{EXPERIMENTAL WORK}

Early in 1977 a research project was started at the University of Auckland to study the behaviour of beams under cyclic loading. The experimental work was in two parts. In the first part, five beam tests were carried out to investigate the influence of shear stress level on the performance of plastic hinge zones. In the second part the effect of a different reinforcement grade was studied as well as various methods of improving the performance in shear. In this paper only the results from the first series of tests are presented.

In the beams the shear stress level was systematically varied by changing the span to depth ratio. The flexural steel arrangement was kept constant in all beams except the last (3A) in which the area of bottom steel was reduced, see Fig. 1 .

The test beams were made in units, each unit consisting of two cantilever beams springing from a central concrete block representing a stiff column. This block was stressed down to the strong floor with Macalloy bars enabling the beams to be tested independently. The reinforcement in the two beams was continuous through the central block. To prevent progressive yielding in this zone two $10 \mathrm{~mm}$ reinforcing bars were welded to each continuous bar of flexural beam reinforcement (see Fig. 1).

In all beams mild steel reinforcement was used which had a minimum specified yield strength of $275 \mathrm{MPa}$. The stirrups were designed to carry all the shear and to hold each bar of flexural reinforcement at $100 \mathrm{~mm}$ centres against buckling. The concrete was purchased from a local ready mix firm and was required to have a minimum strength of $30 \mathrm{MPa}$ at 28 days. To enable flexural strains in the reinforcement to be measured by a $100 \mathrm{~mm}$ mechanical strain gauge, $30 \mathrm{~mm}$ long steel studs were welded to the reinforcement. Before casting, plastic tubes were fitted over the studs, which were withdrawn when the concrete had hardened leaving a clear gap round each stud.

Details of the test beams are shown in Fig. 1 and further information is given in Table 1.

\subsection{LOADING SEQUENCE AND MEASUREMENTS}

In all the beams except $1 \mathrm{~A}$ and $2 \mathrm{~B}$ the tests were initiated by loading to threequarters of the theoretical yield flexural capacity in each direction for two complete cycles (see Fig. 2). In the first beam, lA, a malfunction of the load measuring equipment resulted in the beam being overloaded to the extent that the steel yielded in the first half cycle. Consequently the test was taken straight to the 2D cycles described in the next paragraph. Due to error beam 2B was initially cycled at load levels close to the theoretical ultimate. Some yielding occurred in the second of these cycles. In all the beams the deflection was monitored at a point located at a distance of $1100 \mathrm{~mm}$ from the beam springing. In the first two ( $I A$ and $1 B$ ) the displacement at this reference point was plotted against load and the deflection corresponding to the three quarter theoretical yield load level was assessed. This was then scaled, assuming linear behaviour, to give the theoretical displacement at the calculated yield load. The scaled value, which was assessed as $6 \mathrm{~mm}$, was taken as the ductility one displacement (1D), and it was used for all beam tests. Reanalysis of the data indicates that this displacement was approximately 10 per cent too high.

After the first load controlled cycles, displacements were imposed on the beams. At each level the beam was displaced in both directions for two complete cycles, see Fig. 2. Displacement ductilities of $2,4,6$ and 8 were used, corresponding to $12,24,36$ and $48 \mathrm{~mm}$ deflections at the reference point $1100 \mathrm{~mm}$ from the beam springing. These load stages are subsequently referred to as the 2D, 4D, 6D and $8 \mathrm{D}$ ductilities. The + and - signs used in the figures refer to the direction of loading, and the $i$ and $i i$ symbols refer to the first and second cycles. When the first two 8D cycles had been completed either two further cycles of $8 D$ were applied followed by two 10D cycles or the tests went straight to the IOD level. The loading sequence is illustrated in Fig. 2 .

Each beam test lasted about six days. Numerous strain and displacement measurements were made to enable the following values to be determined:

(1) The load deflection curves for the beams at the reference point (1100 $\mathrm{mm}$ from springing), and at the load point,

(2) The strain distribution in the flexural reinforcement at the peak beam displacements (2D, 4D, etc.),

(3) The shear deformation in the beam, and

(4) The changes in length of the beam.

To relate the results of these tests to a typical structure it is necessary to have some idea of the relationship between the ductility measured in these tests and the ductility displacement in a multistorey frame. Such a structure is illustrated in Fig. 3. If a displacement ductility of 4 
is imposed on the frame each bean column unit (such as $A B C D$ ), should be subject to approximately the same ductility demand. The elastic displacement of this unit arises from deformation in both the beams and columns. However, the inelastic deformation occurs only in the beams. Thus if a typical beam is tested by itself a displacement ductility of 6 corresponds to a value of approximately 4 in the equivalent beam column unit, see Fig. 3.

\subsection{BEHAVIOUR OF BEAMS UNDER ELASTIC LOAD}

In the elastic load cycles the cracks were nearly normal to the flexural reinforcement in beams $2 \mathrm{~A}$ and $2 \mathrm{~B}$. These beams had shear stress levels of 1.16 and $0.94 \mathrm{lPa}$ respectively. However, in beams $1 \mathrm{~A}$ and $1 \mathrm{~B}$, which had the higher shear stress levels of 2.21 and $1.56 \mathrm{MPa}$, the cracks were inclined at approximately 45 degrees. In beam $3 \mathrm{~A}$ the tension cracks were inclined on the upper side of the beam which was reinforced with the $20 \mathrm{~mm}$ bars, but were near to vertical on the side containing the $16 \mathrm{~mm}$ flexural reinforcement.

The deflections of the beams at the load and reference points at the 3/4D load levels, or the values extrapolated from the two sets of readings taken immediately below this level, are given in Table 2. The last reading in the nominal elastic load cycles for beam $2 \mathrm{~B}$ has been discarded as the measurements show the flexural steel had yielded in the previous load application. The measured deflections may be compared with the calculated values in the table. The flexural deformations were determined from section properties based on the cracked section. The elastic modulus of the concrete was taken as $25000 \mathrm{MPa}$ (Draft N.Z. code $(4)$ value $25700 \mathrm{lPa})$. To allow for the deformation of the flexural reinforcement in the central block the beam length was taken as the free length plus $200 \mathrm{~mm}$. This additional length was chosen as it was reasonably consistent with the additional length required to give the same rotation as the pull out of the reinforcement from the central block. The rotation of the beam supports and central column block was not monitored during the test, and it cannot be accurately calculated. The value listed in the table for this represents the best estimate the writers can make.

Shear deformation in a beam consists of two components, the first of which is caused by the deformation of the stirrups and the concrete in diagonal compression. A method of calculating this deformation is given in reference 1. The second component arises from shear lag in the tension zone increasing the flexural tension forces. This occurs with diagonal cracking, and it is illustrated in Fig. 4. It may be seen from the free body diagram in this figure that the increase in the flexural tension force depends upon the length of the diagonal crack and the magnitude of the stirrup forces. If the longitudinal projection of this crack is taken as the flexural leverarm $j d$, then with no shear resisted by stirrups the increase in flexural tension force is equal to the shear $V$. However, if all the shear is resisted by stirrups the increase is reduced to $V / 2$. Strains measured in the flexural tension reinforcement during the elastic load cycles are shown for the first four beam tests in Fig. 5. For beams $I A$ and $I B$ which contained significant diagonal cracking at this load level the measured steel strains are greater than those corresponding to flexural theory alone, and they are in reasonable agreement with the theoretical flexural value plus half the shear. In beams $2 \mathrm{~A}$ and $2 \mathrm{~B}$, which did not contain major diagonal cracks the flexural strains are generally just below the value from flexural theory. This is due to the tension stiffening effect of the concrete, in which it carries some of the tension force between the cracks, thus reducing the average strains. In assessing the theoretical deflections an allowance for a shear lag tension force increase of $V / 2$ has been included for beams $I A, I B$ and for the downward loading in beam 37. No allowance has been made in the other beams.

The theoretical and experimentally measured deflections are in reasonable agreement with each other. Inspection of the values for the reference point $1100 \mathrm{~mm}$ from the beam springing illustrates the importance of shear deformation on member behaviour. For beam lA with a theoretical ultimate shear stress level of $2.21 \mathrm{MPa}$, the calculated deformation due to shear effects amounted to $37 \%$ of that due to flexure. However, in the beam with the greatest span over depth ratio $2 \mathrm{~B}$ (lowest shear stress) the theoretical shear deformation is negligible and consequently the total deflection is less than that of $1 \mathrm{~A}$ in spite of the $18 \%$ greater theoretical flexural deformation of $2 \mathrm{~B}$. The experimental deflection measurements follow the theoretical trends. The magnitude of the shear deformation in the beams with the higher shear stress levels makes it difficult to assess both the displacements corresponding to a ductility of one and its significance.

\subsection{BEHAVIOUR OF BEAMS UNDER INELASTIC LOAD CYCLES}

In the displacement controlled cycles yield of the reinforcement caused the cracks to open up. After a few cycles they remained open over the full depth of the beam. In the beams with the higher shear stress levels the concrete spalled off the reinforcement in the $6 \mathrm{D}$ cycles. With the lower shear stress levels this was delayed to the end of the 8D cycles. Spalling was followed by the breaking up of the concrete in the web of the beam. After a number of further load cycles the concrete disintergrated and fell out of the web, and this was accompanied by a sharp decrease in the load resisted by the beam.

The relative performance of the beams may be assessed visually from the load deflection curves; the fatter the loops the more energy is dissipated by the hinge and the better is the performance. The load deflection curves for the beams with the highest and lowest shear stress levels are shown in Fig. 6. A comparison of these shows that the higher shear stress level resulted in a more pinched load deflection characteristic and it reduced the number of cycles sustained by the beam before serious stiffness degradation occurred at low load levels and appreciable strength degradation 
TABLE 1: DETAILS OF TEST BEAMS

\begin{tabular}{|c|c|c|c|c|c|c|c|c|c|c|c|}
\hline \multirow[b]{2}{*}{ Beam } & \multirow{2}{*}{$\mathrm{fPa}_{\mathrm{y}^{\prime}}$} & \multirow{2}{*}{$\mathbf{F P a} \mathbf{f}^{\prime}$} & \multirow{2}{*}{${ }_{\operatorname{mm}}^{\ell}$} & \multirow{2}{*}{\multicolumn{3}{|c|}{$\begin{array}{l}\text { St1rrup bar } \\
\text { d1ameters } \\
\text { a } 8 \text {. c }\end{array}$}} & \multicolumn{5}{|c|}{ Theoretica1 Values $\phi$} \\
\hline & & & & & & & $\begin{array}{l}v_{\mathrm{s}} \\
\mathrm{kN}\end{array}$ & $\begin{array}{l}M_{u} \\
k N m\end{array}$ & \begin{tabular}{|l|}
$\mathrm{P}_{\mathrm{u}}{ }^{\alpha}$ \\
$\mathrm{kN}$
\end{tabular} & $\mathrm{MPa}_{\mathrm{v}}^{\mathrm{v}_{\mathrm{v}}}$ & $\sqrt{\mathrm{E}_{\mathrm{c}}^{\mathrm{T}}}$ \\
\hline $1 \mathrm{~A}$ & 290 & $30^{*}$ & 923 & 10 & 6 & 6 & 294 & 183.6 & 198.9 & 2.21 & 0.41 \\
\hline IB & 290 & $30 *$ & 1329 & 6 & 10 & 6 & 233 & 183.6 & 138.1 & 1.56 & 0.29 \\
\hline $2 \mathrm{~A}$ & 280 & 34.7 & 1735 & 6 & 6 & 6 & 172 & 178.4 & 102.8 & 1.16 & 0.19 \\
\hline $2 B$ & 280 & 34.7 & 2142 & 6 & 6 & 6 & 172 & 178.4 & 83.3 & 0.94 & 0.16 \\
\hline 3 A top & 280 & 27.7 & 1329 & 6 & 10 & 6 & 233 & 174.9 & 131.6 & 1.49 & 0.28 \\
\hline bot & $29 B$ & & & & & & & 122.9 & 92.4 & 1.05 & 0.20 \\
\hline
\end{tabular}

1 Theoretical values using Whitney stress block for flexurab calculations

* Test cylinders incorrectly cured $f_{c}^{\prime}$ taken as $30 \mathrm{MPa}$

a Dead load of beam neglected

$v_{s}$ Shear capacity of web reinforcement

$f_{y}$ Yield of flexural reinforcement

$f_{c}^{\prime}$ cyilinder atrength of concrete.

See F1g. 1 for further deta11s.

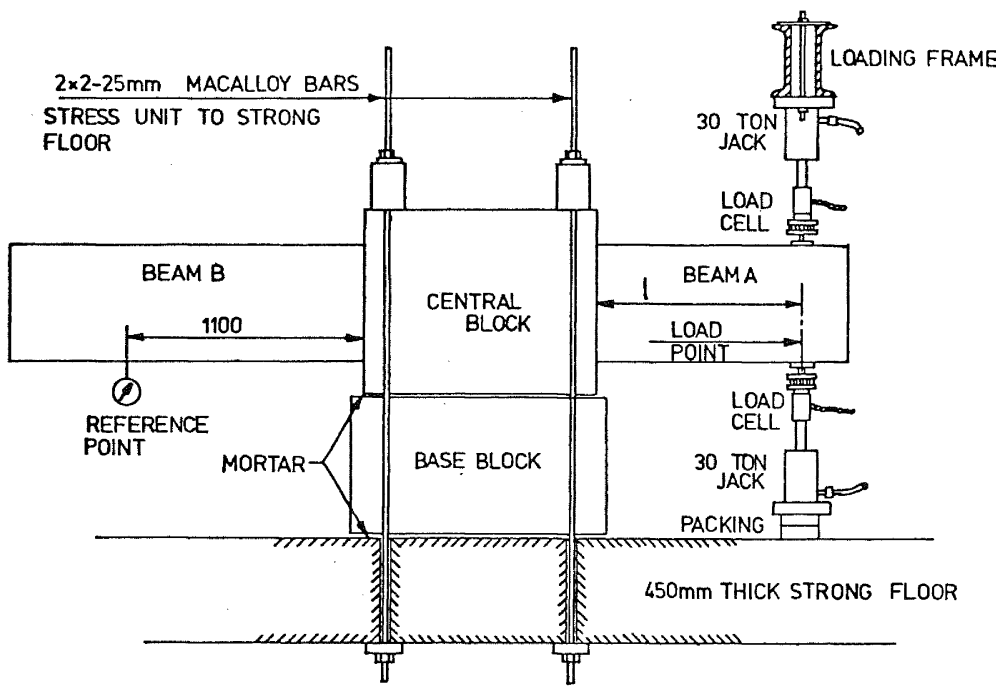

(a) Test Arrangement

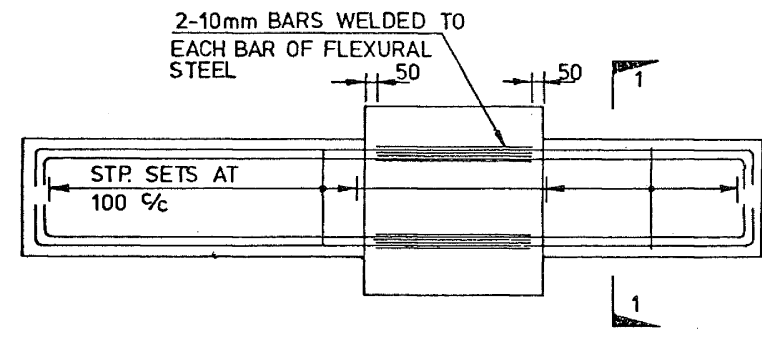

TABLE 2: MEASURED AND COMPUTED DEFLECTIONS AT LOAD AND REFERENCE POINTS DURING ELASTIC LOAD CYCLES

Measured deflections at reference point.

\begin{tabular}{|c|c|c|c|c|c|c|}
\hline \multirow{2}{*}{$\begin{array}{l}\text { Load } \\
\text { Cycle }\end{array}$} & \multicolumn{5}{|c|}{ Beam } & \\
\hline & $1 \mathrm{~A}$ & $1 \mathrm{~B}$ & $2 \mathrm{~A}$ & $2 B$ & 3 & \\
\hline $\begin{array}{l}+J / 41 \\
-3 / 41 \\
+3 / 411 \\
-3 / 411\end{array}$ & $\begin{array}{l}4.0 \\
= \\
-\end{array}$ & $\begin{array}{r}4.9 \\
-4.2 \\
4.9 \\
-4.4\end{array}$ & $\begin{array}{r}3.6 \\
-3.6 \\
3.7 \\
-3.6\end{array}$ & $\begin{array}{r}3.7 \\
-3.5 \\
3.8 \\
-\end{array}$ & $\begin{array}{l}2.2 \\
2.4\end{array}$ & $\begin{array}{r}-4.0 \\
-3.6 \\
\end{array}$ \\
\hline Average & 4.0 & 4.6 & 3.6 & 3.7 & 2.3 & 3.80 \\
\hline \multicolumn{7}{|c|}{ Measured deflections at load point. } \\
\hline $\begin{array}{l}+3 / 41 \\
-3 / 4 i \\
+3 / 111 \\
-3 / 411\end{array}$ & $\begin{array}{c}3.50 \\
5 \\
-\end{array}$ & $\begin{array}{r}5.9 \\
-4.9 \\
5.8 \\
-5.4\end{array}$ & $\begin{array}{r}5.5 \\
-5.2 \\
5.7 \\
-5.8\end{array}$ & $\begin{array}{r}8.8 \\
-8.0 \\
8.5 \\
-\end{array}$ & $\begin{array}{l}2.8 \\
2.9\end{array}$ & $\begin{array}{l}-4.4 \\
-4.4\end{array}$ \\
\hline Average & 3.50 & 5.5 & 5.6 & 8.4 & 2.9 & 4.4 \\
\hline
\end{tabular}

Calculated deflections at reference point

\begin{tabular}{|c|c|c|c|c|c|c|}
\hline $\begin{array}{l}\text { flexure } \\
\text { shear } \\
\text { shear } 2 \\
\text { f1xity }\end{array}$ & $\begin{array}{l}2.50 \\
0.42 \\
0.50 \\
0.36\end{array}$ & $\begin{array}{l}2.76 \\
0.20 \\
0.35 \\
0.32\end{array}$ & $\begin{array}{l}2.81 \\
= \\
0.30\end{array}$ & $\begin{array}{l}2.94 \\
=- \\
0.28\end{array}$ & $\begin{array}{c}2.52 \\
- \\
- \\
0.22\end{array}$ & $\begin{array}{l}2.80 \\
0.19 \\
0.33 \\
0.31\end{array}$ \\
\hline Total & 3.78 & 3.63 & 3.11 & 3.22 & 2.74 & 3.63 \\
\hline
\end{tabular}

Calculated deflections at load point

\begin{tabular}{|c|c|c|c|c|c|c|}
\hline $\begin{array}{l}\text { flexure } \\
\text { shear } \\
\text { shear } 2 \\
\text { f1xity }\end{array}$ & $\begin{array}{l}2.03 \\
0.42 \\
0.36 \\
0.32\end{array}$ & $\begin{array}{l}3.55 \\
0.24 \\
0.51 \\
0.37\end{array}$ & $\begin{array}{l}5.35 \\
= \\
0.42\end{array}$ & $\begin{array}{l}7.70 \\
= \\
0.47\end{array}$ & $\begin{array}{l}3.25 \\
- \\
- \\
0.25\end{array}$ & $\begin{array}{l}3.60 \\
0.19 \\
0.48 \\
0.36\end{array}$ \\
\hline Tota 1 & 3.13 & 4.67 & 5.77 & 8.17 & 3.50 & 4.63 \\
\hline
\end{tabular}

flexure $=$ flexural deformation

shear 1 - shear deformation due to web members

shear 2 - deformation due to shear lag

fixity - deformation due to rotation of unit supporta.

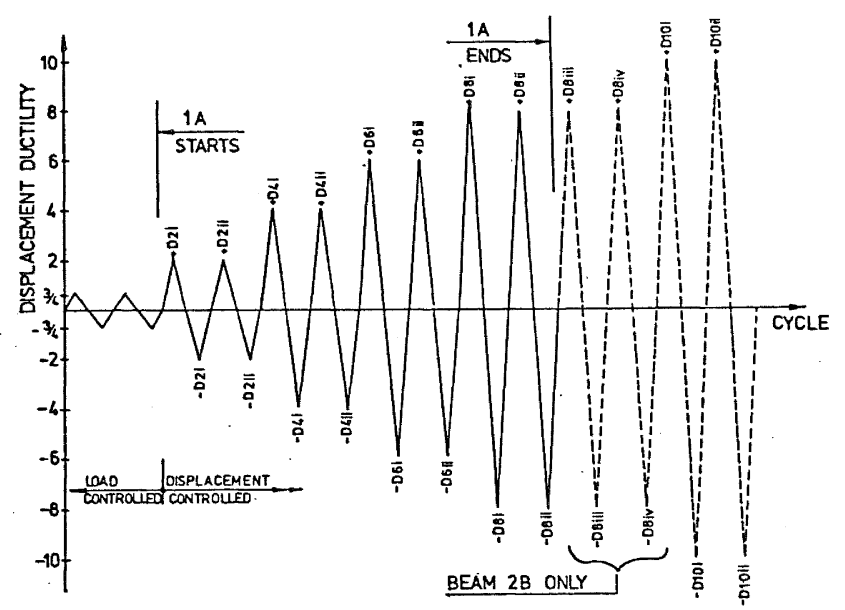

FIGURE 2: LOADING SEQUENCE

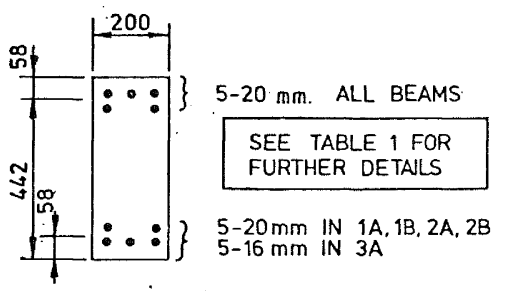

SECTION $1-1$

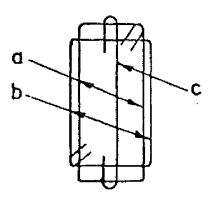

STP. SET

(b) Reinforcement Details 

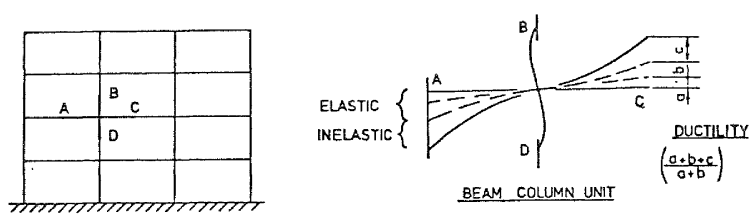

REGULAR FRAME

$a=$ ELASTIC DISPL. DUE TO COL. DEFORMATION

$c=$ INELASTIC DISPL. DUE TO BEAM DEFORMATION

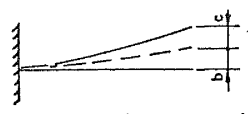

BEAM

$\left(\frac{a+b}{c}\right)$
EQUILIBRIUM REQUIREMENTS

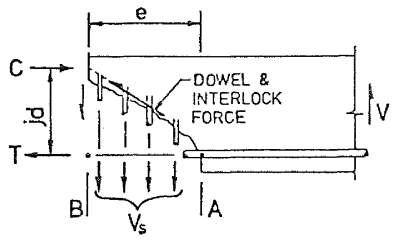

$T j d=M_{a}+V e-V_{s} e / 2$ FOR $V=V_{5}$ AND $e=j d$ $T=M a / j d+V / 2, C=M b / j d-V / 2$ WHERE $M_{0}=$ b. M. AT A $M_{b}=b \cdot m$. AT $B$

FIGURE 3: DISPLACEMENT DUCTILITY IN A BEAM AND A BEAM COLUMN UNIT

FIGURE 4: SHEAR LAG DUE TO DIAGONAL CRACKING
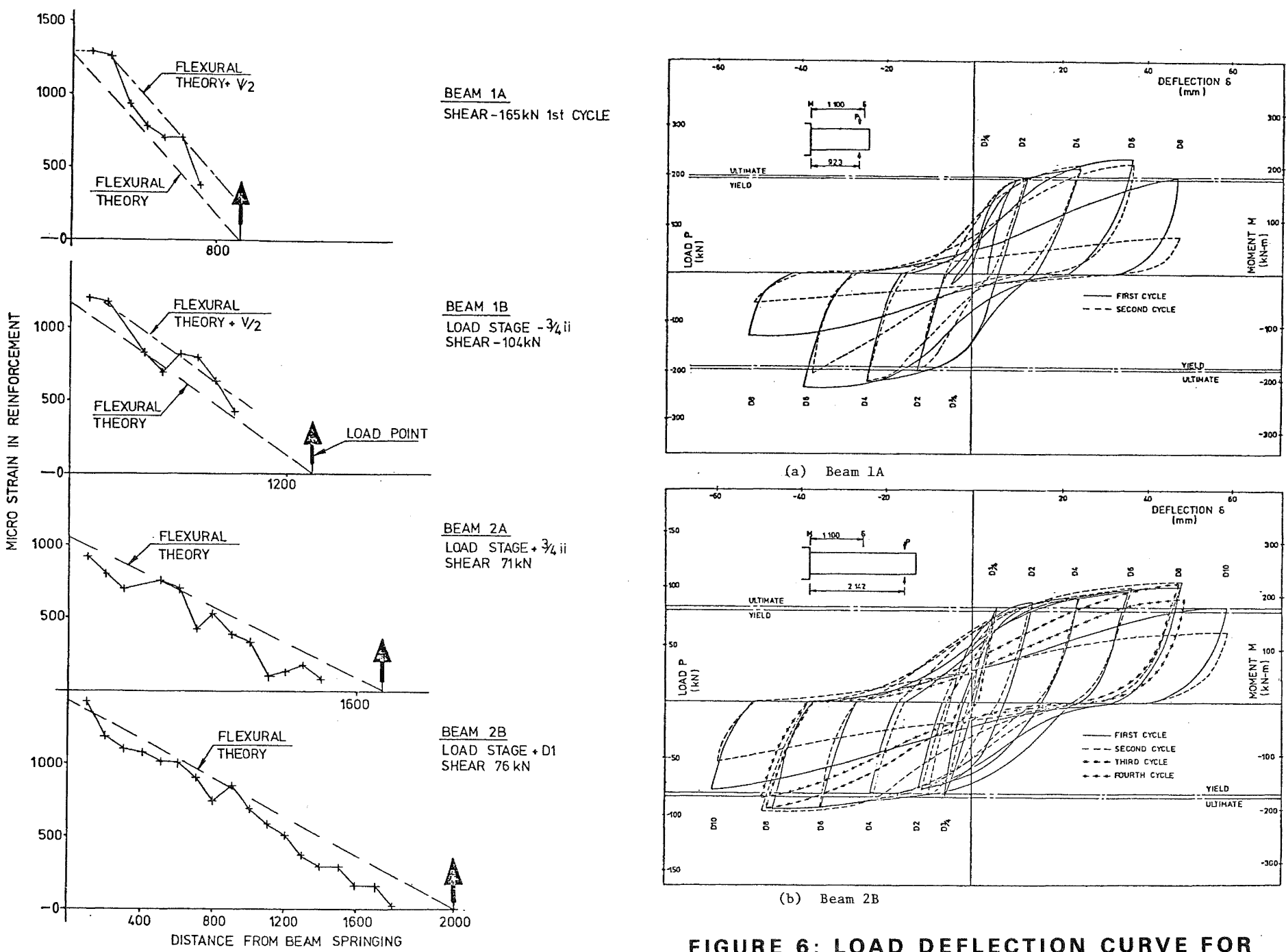

(a) Beam $1 \mathrm{~A}$

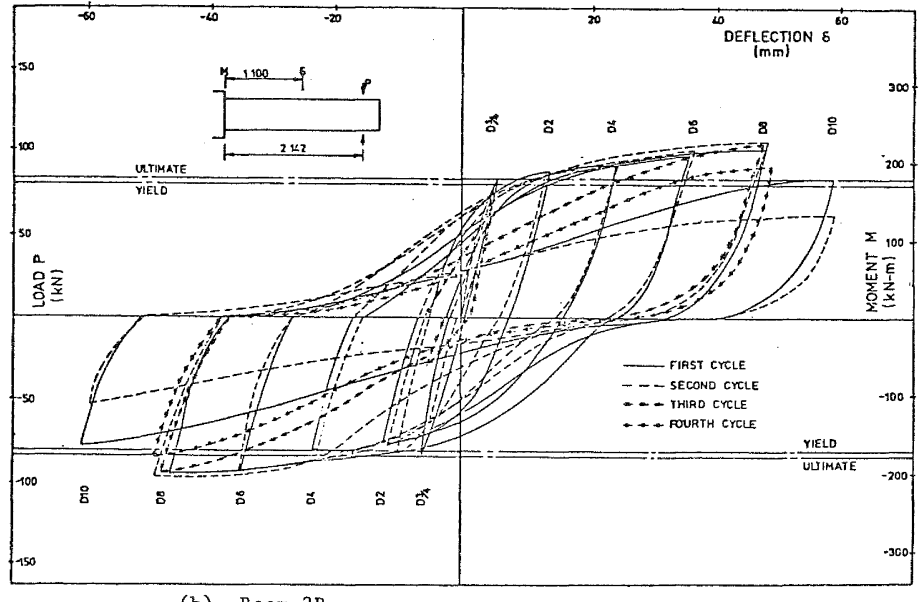

(b) Beam 2B

FIGURE 6: LOAD DEFLECTION CURVE FOR REFERENCE POINT FOR BEAMS 1A AND 2B 

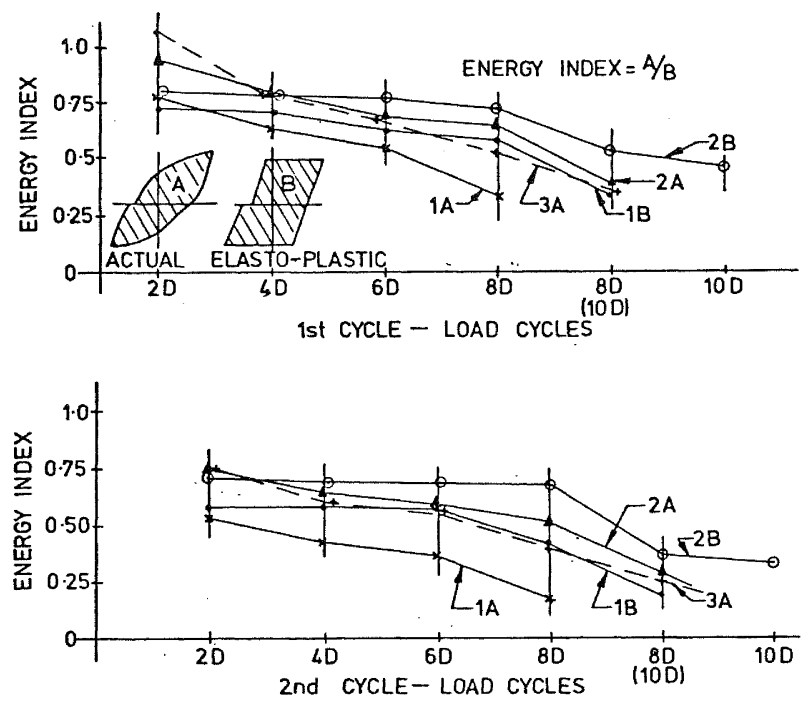

FIGURE 7: VARIATION OF ENERGY INDEX WITH LOAD CYCLE

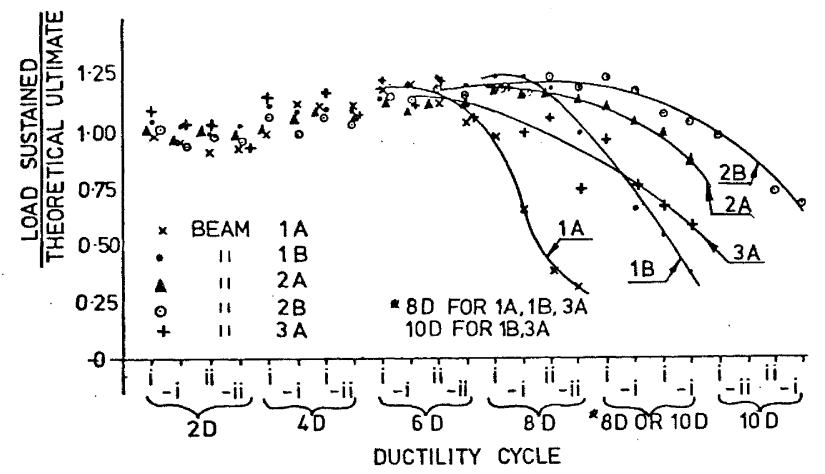

FIGURE 9: VARIATION IN LOAD SUSTAINED AT MAXIMUM DISPLACEMENT WITH LOAD CYCLE

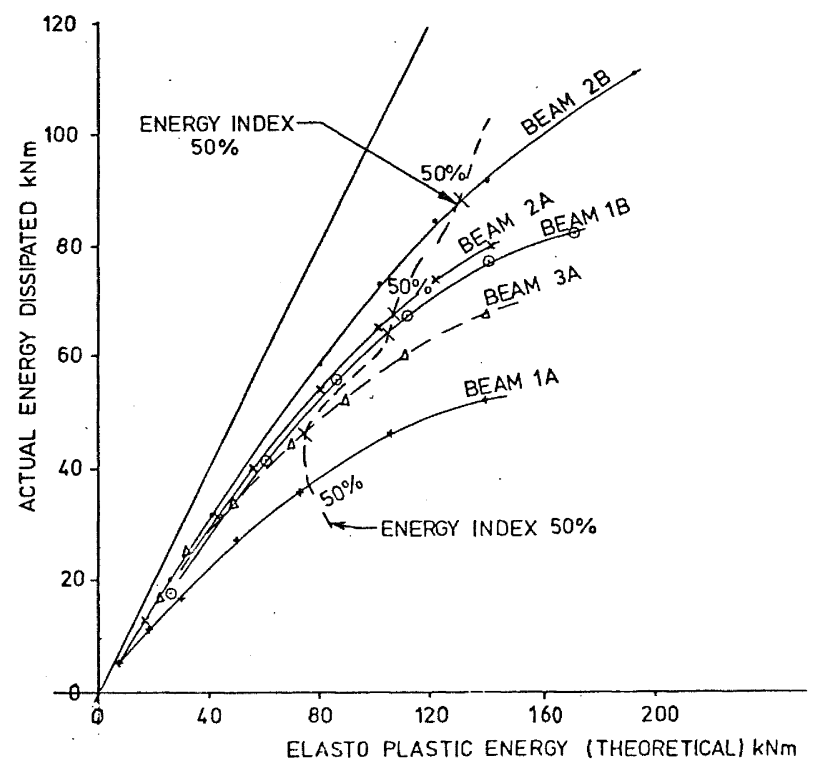

FIGURE 8: ENERGY DISSIPATED IN BEAMS COMPARED WITH EQUIVALENT ENERGY IN ELASTO-PLASTIC BEAM
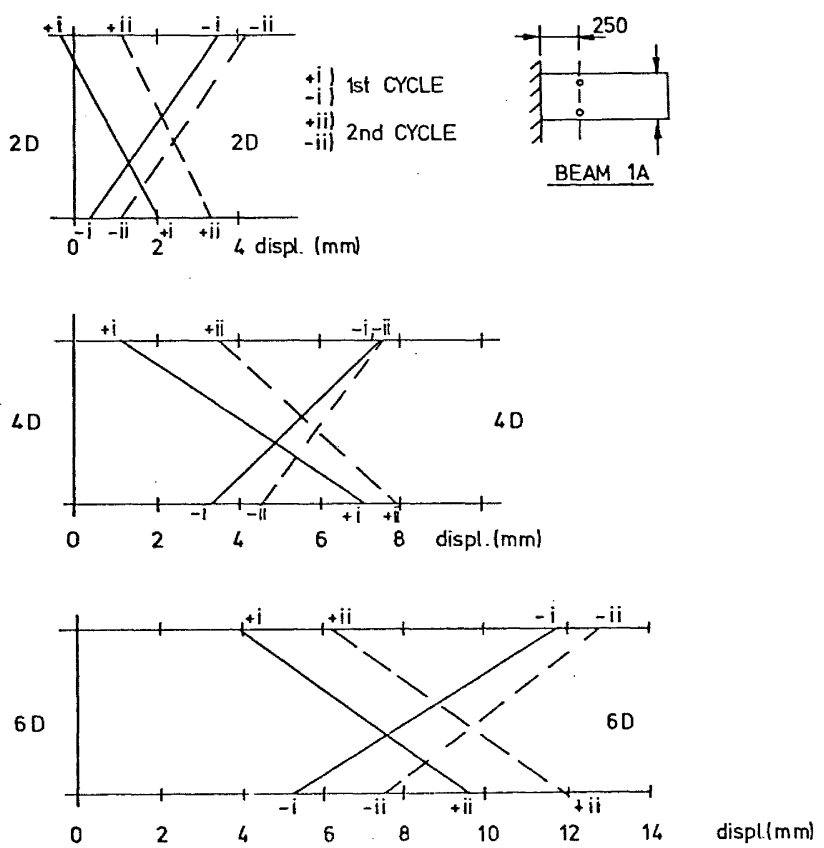

FIGURE 10: FLEXURAL STRAINS - BEAM 1A 
occurred at the maximum displacements. The load deflection curves for the beams with intermediate shear stress levels follow these trends.

To allow a numerical comparison of the different beams to be made a value which is referred to as the energy index was calculated. This was defined as the area under the load deflection curve in a particular cycle divided by the area sustained by a beam behaving in an elasto plastic mode. In Fig. 7 the variation of energy index with load cycle is shown. It may be seen that the higher the shear stress level the smaller the energy index; that is the load deflection loop is more pinched in form. Fig. 8 shows the actual energy dissipated by the beam plotted against the theoretical elasto plastic value. This clearly indicates the poorer energy dissipation in the beams with the higher shear stress levels.

In Fig. 9 the variation in the load sustained at peak displacement for the different load cycles is shown. The higher shear stress levels may be seen to reduce the number of cycles sustained by the beam before strength degradation occurs. This figure shows that as the test progressed the load sustained by the beams increased above the theoretical ultimate level based on the yield strength of the reinforcement. The peak increase was between 18 and 24 per cent for all beams, and it was sustained in the D6 or 08 load cycles. The average increase in strength above the theoretical load in all the D6 cycles for all five beams was 15 per cent.

Beam 3A differed from the other beams in that the area of bottom steel was reduced to $67 \%$ of the area of top steel. Except for this difference it was essentially the same as beam 1B. The different flexural strengths in each direction lead to the beam being subject to different peak shear stresses depending on the direction of loading. Inspection of Figs. 7,8 and 9 show that the performance of beams $3 \mathrm{~A}$ and $1 \mathrm{~B}$ were almost identical. This was an unexpected result as it is contrary to the suggested design rules in the draft N.Z. code as quoted in equation 1. For the test condition this expression gives an allowable shear stress level of $1.64 \mathrm{MPa}(0.3 \sqrt{\mathrm{f}})$ for beam $1 \mathrm{~B}$ as the value of $r$ is equal to -1 . The corresponding value for beam $3 \mathrm{~A}$ is $2.05 \mathrm{MPa}(0.39 \sqrt{\mathrm{fl}})$ with $r=-0.7$. The actual shear stress levels for the two beams were 1.56 and $1.49 \mathrm{MPa}$ for $1 B$ and $3 A$ respectively. As beam IB was much closer to the proposed limit than $3 A$ its performance could have been expected to be poorer than 3A. This was not the case.

Comparative beam tests at Berkeley (6) have shown that reducing the flexural steel on one side of the beam has two effects. Firstly the shear deformation in the member is slightly reduced due to the smaller shear forces which may be sustained in one direction, and secondly the flexural performance of the member is reduced as the smaller area of steel is more susceptible to buckling. This area of flexural reinforcement tends to be yielded in tension and compression much more than the larger area, and consequently its stiffness is reduced by the Bauschinger effect. This combined with the requirement that part of the compression force must be carried by the concrete causes it to spall prematurely, increasing its susceptibility to buckling.

During the tests the beams were observed to grow in length. This was accompanied by an increase in the shear deformation. The mechanism of growth is described below and illustrated in Fig. 10, where the displacement of a section located $250 \mathrm{~mm}$ away from the springing in beam $1 \mathrm{~A}$ is plotted at different cycles. Under the first half cycle of loading (+2Di) the bottom steel yields in tension and small compressive strains develop in the top steel because the compression force is shared with the concrete. Under the next half cycle of loading $(-2 \mathrm{Di})$ the top steel yields in tension and the bottom steel goes into compression. However, not all the tensile strain in the steel is recovered and the cracks do not fully close. When the reinforcement yields, local slip occurs close to the main cracks. The deformations on the bar plough through the concrete pulling broken material into the cracks. In the low load stages of the next half cycle the cracks are open right through the beam and all the shear is resisted by interface friction. Hence a shearing force is applied to the broken concrete surrounding the reinforcement. The disruption caused by this prevents the material from fitting back into its initial location. Consequently the cracks remain wedged open, and as the beam is cycled it progressively grows in length with the two sides of the cracks being ground against each other. This produces more debris to fill the crack.

The flexural deformation of the hinge zone in the presence of shear causes the beam to grow in length. The opening of the cracks right through the beam reduces the shear stiffness of the member, and consequently this growth is accompanied by an increase in shear deformation. The beam length may stabilise for two different reasons. Firstly the compression reinforcement may buckle, leading to a shortening of the compression zone and hence the beam. Secondly, if the shear deformation increases to a sufficient extent the required flexural deformation reduces, and hence the driving action for growth is removed. Fig. 11 shows the way in which the beam increased in length with cycling. The maximum growth was reached in the $6 \mathrm{D}$ to $8 \mathrm{D}$ cycles, and it varied from 13 to $19 \mathrm{~mm}$ in magnitude.

Fig. 12 shows the proportions of flexural and shear deformation sustained in the test beams at different load stages. Shear deformation is important in all the beams. At the end of the 6D cycles it accounted for approximately 20 per cent of the deformation in beam $2 \mathrm{~B}$ which had the lowest shear stress level (0.94 MPa), while for beam IA which had the highest shear stress level (2.21 MPa) it accounted for 75 per cent of the deformation. The performance of beam $3 \mathrm{~A}$ with the unequal top and bottom steel was very similar to its comparison beam $1 \mathrm{~B}$ which had equal flexural steel areas.

Fig. 13 shows the relationship between the load and shear deformation for beams $2 B$ and $3 A$. These diagrams are similar in form to those reported in the literature $(2,6,7)$. Most of the shear deformation 


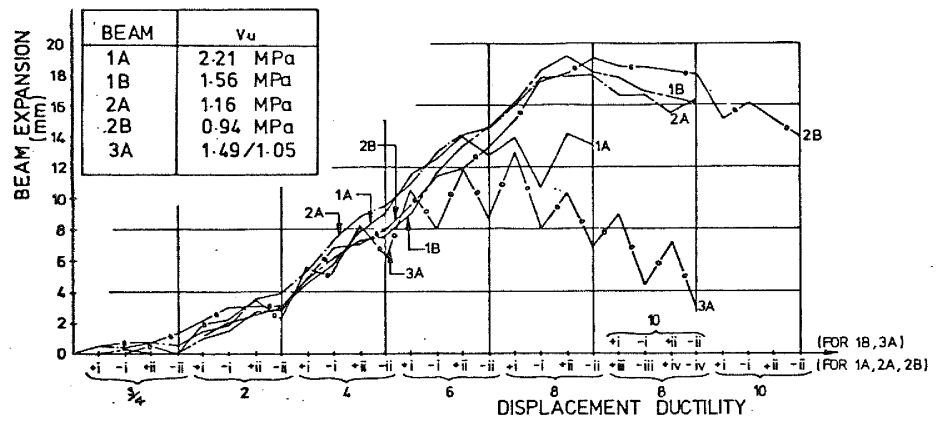

FIGURE 11 GROWTH IN LENGTH OF BEAMS

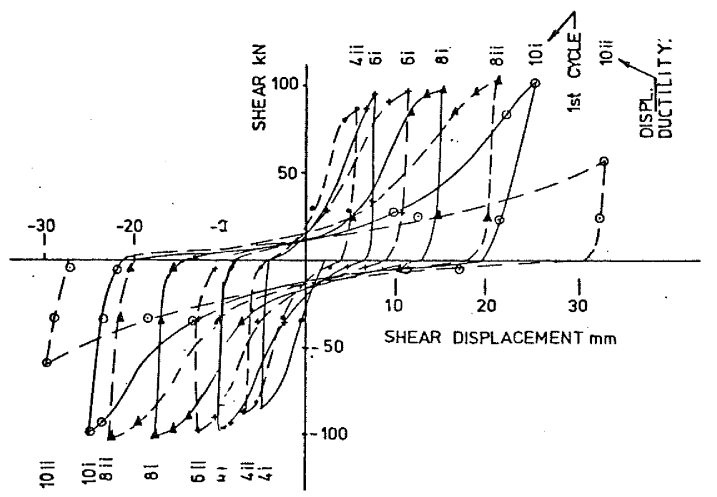

(a) Beam $2 \mathrm{~B}$

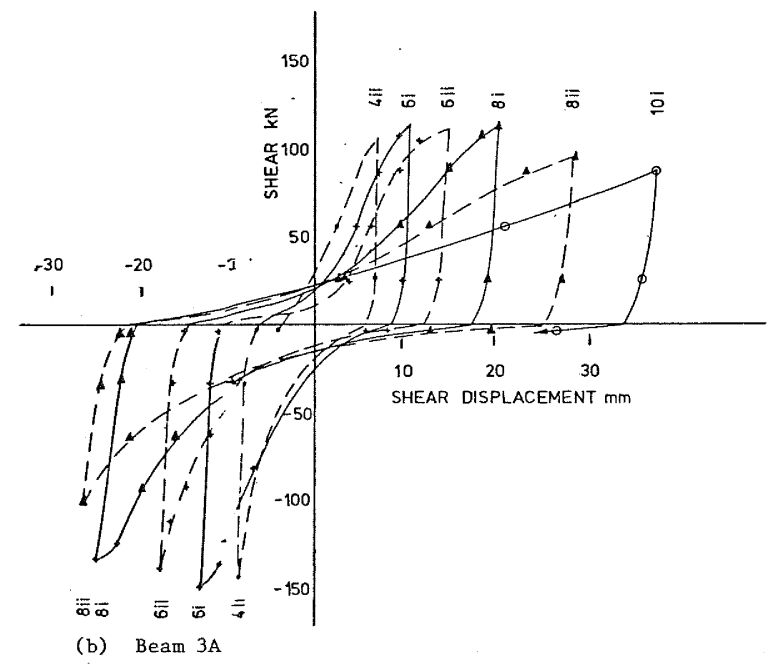

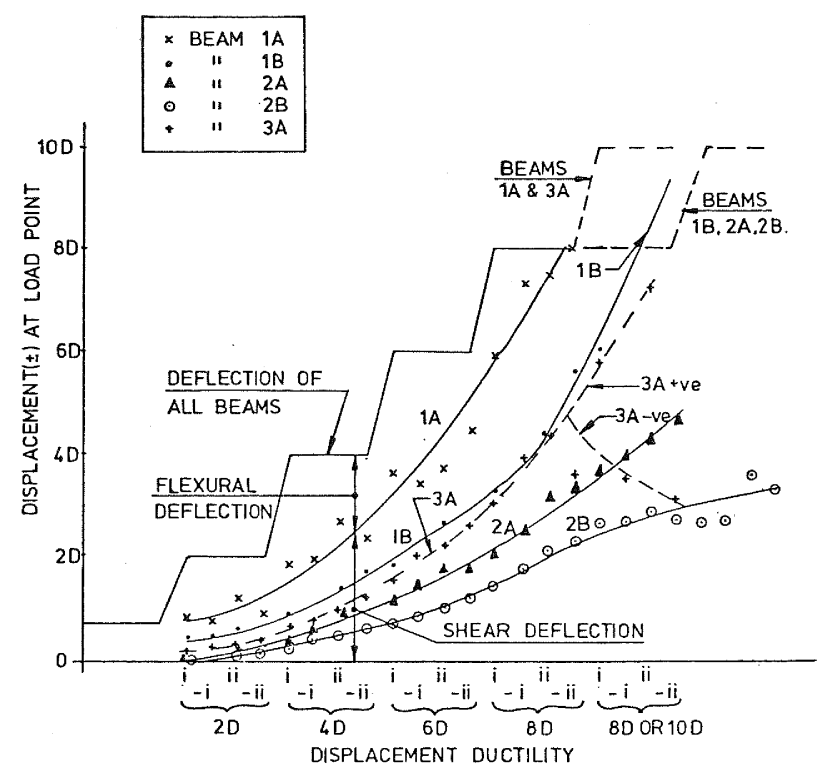

FIGURE 12: PROPORTIONS OF FLEXURAL AND SHEAR DEFORMATION IN BEAMS

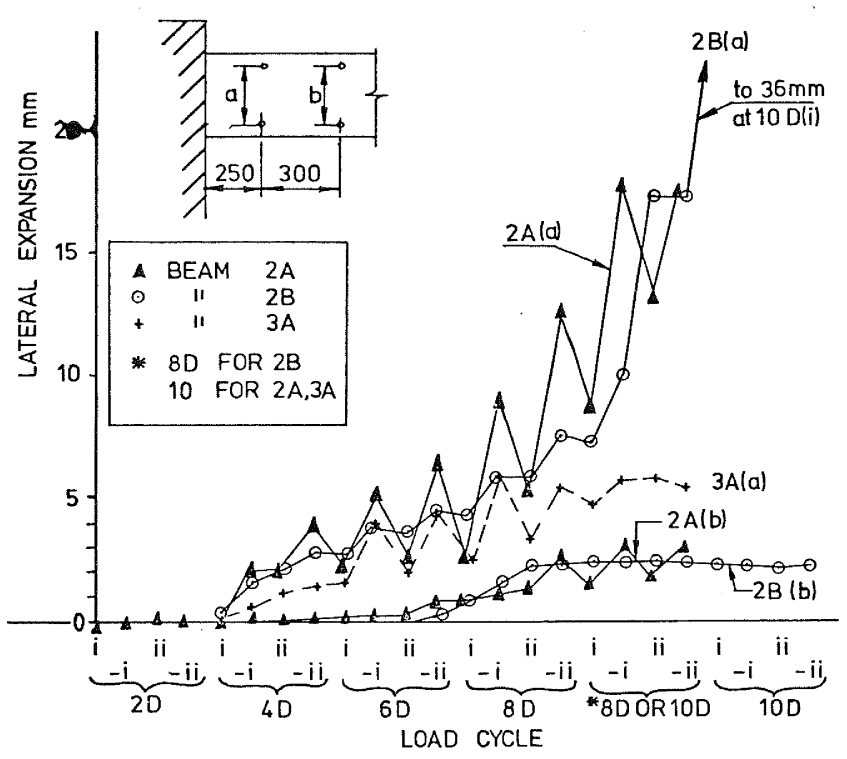

FIGURE 14: CHANGE IN BEAM DEPTH UNDER CYCLIC LOADING 
occurs at low load levels, which gives rise to the characteristic shear pinching of the hysteresis loops, and reduces the energy which may be dissipated by the hinges.

Stirrup strains were not measured during the tests, but the distance between the studs welded to the top and bottom reinforcement was monitored. Changes in this distance may arise from the yield of the stirrups and local buckling of the flexural reinforcement. The growth in the depth of the beams $2 A, 2 B$ and $3 A$ is shown in Fig. 14. The stirrups appear to have yielded after the plastic hinge was well established at the location being examined. The magnitude of the growth in the beam depth is even more surprising than the growth in length of the beams.

\subsection{ANALYSIS OF RESULTS FOR INELASTIC CYCLING OF BEAMS}

The magnitude of shear deformation sustained by a beam could be expected to be a function of the damage sustained and the shear stress level. The damage may be assessed by the dissipated energy. As most of the shear deformation occurs at low load levels a regression analysis was carrieo out for each beam in which the shear deformation in the plastic hinge zone was compared with the dissipated energy to the end of the previous cycle. The hinge shear deformation was taken as the total measured shear deformation minus the extrapolated shear deformation corresponding to the ID displacement. The regression analyses for the five beams gave the following equations:

$$
\begin{aligned}
& \text { Beam IA } v_{\mathrm{u}}=0.41 \sqrt{\mathrm{f}_{\mathrm{C}}^{\top}} \quad r=0.94 \\
& S=0.46 \mathrm{E}+2.50 \\
& \text { Beam 1B } v_{\mathrm{u}}=0.29 \sqrt{\mathrm{f}_{\mathrm{C}}} \quad r=0.98 \\
& S=0.30 E+1.32 \\
& S=0.25 E+1.15 \\
& S=0.18 \mathrm{E}+1.06 \\
& S=0.28 \mathrm{E}+0.40
\end{aligned}
$$

where $\mathrm{S}$ is the shear displacement in $\mathrm{mm}$, $r$ is the coefficient of determination which is a measure of the closeness of fit of the points to the equation, and $\mathrm{E}$ is the dissipated energy in energy units as defined below. An energy unit $(\mathrm{IE})$ is the energy dissipated by an effective length of beam at theoretical ultimate load conditions for moment under monotonic loading when a moment is applied first in one direction and then in the other direction to give one additional yield strain in the flexural tension reinforcements. The value of one unit of energy is given by:

$A_{s} f_{y} \cdot \frac{j d}{(1-k)} \cdot \frac{f_{y}}{E_{s}}+A_{s}^{\prime} f_{y}^{\prime} \cdot \frac{j^{\prime} d}{(1-k)} \frac{f_{y}^{\prime}}{E_{s}}$

where $A_{S}$ is the area of tension steel, jd is the lever arm of the flexural forces, $\mathrm{k}$ is the distance from the centroid of the tension steel to the neutral axis and $f_{y}$ is the yield point of the reinforcement. The superscripted values apply to the reinforcement on the other side of the beam. The values of $j d$ and $k$ are found from standard flexural theory at ultimate load conditions.

These regression equations were adjusted t.c pass through the common ordinate of 1.30 , and a further regression analysis was carried out for the coefficient of $E$ against the average maximum shear stress without regard to sign. The resulting equation for the shear deformation in this series of beams reduces to:

$S=\frac{1.15 v_{u}}{\sqrt{f T}} E+1.30$

Before this expression may be applied to other beams it should be adjusted for the effects of beam depth.

The expression given above is a tentative equation which can only be expected to indicate the order of shear deformation which may be expected. In its derivation many factors have not been considered. In particular the quantity of web reinforcements (which appears to yield in these tests) could be expected to exert a considerable influence on the results, as a change in the area of these would change the magnitude of the confining force. The degree of confinement of the web concrete could also be expected to have an appreciable effect(6).

\subsection{CONCLUSIONS}

(i) The test results show that shear in plastic hinge zones formed under reversed loading conditions has a marked effect on member behaviour. In the test beam 2B, which had the lowest shear stress level $(0.16 \sqrt{\mathrm{fC}})$, the shear deformation at the local point amounted to $20 \%$ of the total at the end of the 6D cycles. For test beam IB $\left(0.29 \sqrt{f_{C}^{\prime}}\right)$ the equivalent proportion of shear deformation was $45 \%$.

(ii) The experimental results show that as the shear stress level increases the performance decreases. To find a rational cut off point for design further work is required. This would involve more detailed analysis of other published test results together with inelastic analyses of structures in which the shear degradation effects are modelled. However, pending such a study some indication of a suitable cut off shear stress level may be gained from the results. Inspection of Figures 7 and 8 , which show the energy performance, and Figure 9, which gives the strength degradation, show a gradual decrease in performance as the shear stress increases from $0.16 \sqrt{f_{C}^{\prime}}$ to $0.29 \sqrt{f_{C}^{\prime}}$, but there is a marked decrease from this level to the test at $0.41 \sqrt{f_{C}^{\top}}$. This suggests a cut off level of about $0.29 \sqrt{f_{C}}$. The proposed limit in the draft N.Z. Code $(4)$ of $0.3 \sqrt{f_{C}^{!}}$for the case of equal shears in each direction fits in with this observation.

(iii) The performance of beam 3A, with the unequal flexural steel areas, was not as 
good as was expected from the draft code expression which gives the limiting shear stress levels in beams without diagonal reinforcement (equation 1). However, this was only one test. Further tests where the shear force in each direction is different is required to clarify this aspect.

(iv) All beams grew appreciably in length under cyclic loading (see Fig. 11). This could have important implications for the performance of frame structures under seismic conditions. This growth must be resisted by slabs and columns. The magnitude of the axial load induced in the beams due to this restrain depends upon its axial stiffness. The expansion of the beams appears to be largely due to the wedging action of displaced aggregate particles in the cracks. If the expanded beam is not stiff then there would be little axial load induced and little growth in an actual frame structure. Under these conditions the small axial load would give a small increase in the moment capacity of the section. However, as the growth is limited wide cracks could not form right through the beams as in these tests, and consequently the sliding shear strength could well be considerably greater than was observed in the work (such as described in this paper) where there is no restraint to growth.

If the aggregate wedging action gives a stiff beam for axial load as it grows then the restraint would not prevent the growth. Consequently the columns would be pushed out from the centre of the building increasing the $\mathrm{P}-\Delta$ effect in these. In addition as high axial loads would be induced in the beam they could be expected to give a considerable increase in the moment capacity of the beams. This would increase the likelihood of a column sway failure mechanism.

\section{ACKNOWLEDGEMENTS}

The writers are grateful to the MWD who provided financial assistance for the project. Mr. Ian Armstrong of the MWD Auckland District office gave valuable assistance in setting up this project, and Mr. Neil Metcalf and his staff from the same office very kindly assisted by tracing the diagrams in this paper.

\section{REFERENCES}

1. Paulay, T., "Design Aspects of Shear Walls for Seismic Areas", Research Report 74-11, Civil Engineering Department, University of Canterbury, (Or R. Park and T. Paulay, "Reinforced Concrete Structures", Chapter 12. Published John Wiley and Sons, 1975.)

2. Bertero, V. V., and Popov, E. P., "Hysteretic Behaviour of Ductile MomentResisting Reinforced Concrete Frame Components", EERC 75-16 April 1975, University of California, Berkeley.

3. Paulay, T., "Shear Strength Requirements", Bulletin of the N.Z. Soc. for Earthquake Engineering, Vol. 10, No. 2, June 1977.

4. S.A.N.Z. Draft N.Z. Standard - "Code of Practice for the Design of Reinforced Concrete Structures", DZ 3101 Pt. 1, 1978 - Standards Assoc. of N.Z.

5. Brown, R. H. and Jirsa, J. P., "Reinforced Concrete Beams Under Load Reversals", Proceedings ACI Vol. 68, No. 5, May 1971.
6. Ma, S. M., Bertero, V. V. and Popov, E.P., "Experimental and Analytical Studies on the Hysteretic Behaviour of Reinforced Concrete Rectangular and T-Beams", Report No. EERC 76-2 May 1976, University of California.

7. Bull, I. N., "The Shear strength of Relocated Plastic Hinges", Research Report 78/11 Feb. 1978, Department of Civil Engineering, Canterbury University.

This paper was presented at the South Pacific Regional Conference on Earthquake Engineering held in wellington on 8,9 and 10 May, 1979. 